\title{
On the estimation of physical height changes using GRACE satellite mission data - A case study of Central Europe
}

\author{
Walyeldeen Godah, Malgorzata Szelachowska*, Jan Krynski \\ Institute of Geodesy and Cartography \\ Centre of Geodesy and Geodynamics \\ 27 Modzelewskiego St., 02-679 Warsaw, Poland \\ e-mails: walyeldeen.godah@igik.edu.pl; malgorzata.szelachowska@igik.edu.pl; jan.krynski@igik.edu.pl
}

Walyeldeen Godah: https://orcid.org/0000-0002-5616-0770

Małgorzata Szelachowska: https://orcid.org/0000-0002-6421-7589

Jan Kryński: https://orcid.org/0000-0003-0695-9821

* Coresponding author: Małgorzata Szelachowska

Received: 12 July 2017 / Accepted: 4 September 2017

\begin{abstract}
The dedicated gravity satellite missions, in particular the GRACE (Gravity Recovery and Climate Experiment) mission launched in 2002, provide unique data for studying temporal variations of mass distribution in the Earth's system, and thereby, the geometry and the gravity field changes of the Earth. The main objective of this contribution is to estimate physical height (e.g. the orthometric/normal height) changes over Central Europe using GRACE satellite mission data as well as to analyse them and model over the selected study area.

Physical height changes were estimated from temporal variations of height anomalies and vertical displacements of the Earth surface being determined over the investigated area. The release 5 (RL05) GRACE-based global geopotential models as well as load Love numbers from the Preliminary Reference Earth Model (PREM) were used as input data. Analysis of the estimated physical height changes and their modelling were performed using two methods: the seasonal decomposition method and the PCA/ EOF (Principal Component Analysis/Empirical Orthogonal Function) method and the differences obtained were discussed. The main findings reveal that physical height changes over the selected study area reach up to $22.8 \mathrm{~mm}$. The obtained physical height changes can be modelled with an accuracy of $1.4 \mathrm{~mm}$ using the seasonal decomposition method.
\end{abstract}

Keywords: GRACE, height anomaly variations, vertical displacements, physical height changes 


\section{Introduction}

Since the early years of this millennium, the estimation of temporal mass variations in the Earth's system using data from satellite gravimetry missions has become one of the most important investigations of the Earth sciences. In particular, the research concerning Earth's dynamics has extremely been revolutionized since the launch of the GRACE (Gravity Recovery And Climate Experiment) satellite gravimetry mission in 2002 (e.g. Tapley et al., 2004). The GRACE satellite gravimetry mission brought a unique opportunity for the determination of temporal mass variations within the Earth's system. The mission concept, including theoretical background, as well as impressive scientific results, have widely been demonstrated by many authors, e.g. in the review given by Wouters et al. (2014). The GRACE Follow-on (GRACE-FO) mission is planned to launch in the period between December 2017 and February 2018 (see https://gracefo.jpl.nasa.gov/) for the sustainable long-term monitoring of temporal mass variations within the Earth system.

The GRACE mission revealed important information for the height system and its temporal variations. For example, Rangelova (2007), Rangelova and Sideris (2008), Rangelova et al. (2010), Krynski et al. (2014) demonstrated the usefulness of GRACE mission data for the determination, analysis and modelling of temporal variations of geoid heights. Moreover, GRACE mission data indicated very useful information related to the elastic ground loading deformation in response to the Earth mass variations. Many authors have proved that the estimated ground displacements using GRACE mission data are in a good agreement with the corresponding ones determined from other space geodetic techniques, e.g. Kusche and Schrama (2005), van Dam et al. (2007), Pan et al. (2016), Tan et al. (2016), Wang et al. (2016), Gua et al. (2017) for the Global Navigation Satellite System (GNSS) and Eriksson and MacMillan (2014) for the Very Long Baseline Interferometry (VLBI).

Temporal variations of geoid heights or height anomalies and temporal variations of vertical displacements of the physical surface of the Earth obtained from GRACE mission data could play an important role in the estimation of physical height changes. The main objective of this contribution is to estimate physical height changes over Central Europe using GRACE satellite mission data. It is also aimed at the analysis and modelling of the estimated physical height changes over the selected study area.

\section{Study area and data used}

Taking into the consideration the spatial resolution of the GRACE mission data, Central Europe, bounded by parallels of $43.5^{\circ} \mathrm{N}$ and $55.5^{\circ} \mathrm{N}$ and meridians of $4.3^{\circ} \mathrm{E}$ and $25.7^{\circ} \mathrm{E}$, has been divided into sixteen equal areas of $\sim 334 \times 334 \mathrm{~km}^{2}$, corresponding to $3^{\circ} \times 3^{\circ}$ on the equator. The study area, including those sixteen subareas and major river basins, is depicted in Figure 1. It should be mentioned that locations of those subareas coincide with the locations of the release 5 global mass concentration (mascons) 
solutions provided by the Jet Propulsion Laboratory (JPL RL05M), representing spherical caps of $3^{\circ} \times 3^{\circ}$ on the equator equal areas (Watkins et al., 2015), which are planned to be used in the next authors' investigations. Figure 1 indicates that nine subareas are completely inland areas while remaining seven subareas are located over both land and sea.

The monthly release 5 (RL05) GRACE-based GGMs developed by the German Research Center of Geosciences (GeoForschungsZentrum (GFZ); Dahle et al., 2014) were used for the determination of temporal variations of height anomalies and vertical displacements at the centre points of the aforementioned sixteen subareas (cf. section 3.1). The GFZ RL05 GRACE-based GGMs without gaps are available for the period from January 2004 to December 2010. Thus, this period has been considered in this investigation. In order to reduce noise, which is especially strong at higher degrees spherical harmonics of these GGMs, the decorrelation (DDK3) filter (Kusche, 2007; Kusche et al., 2009) has been applied. In addition, load Love numbers, calculated using the Preliminary Reference Earth Model (PREM; Dziewonski and Anderson, 1981), have been used for the estimation of the Earth's surface displacements that are induced from surface mass loads. The numerical values of load Love numbers were obtained from Wang et al. (2012).

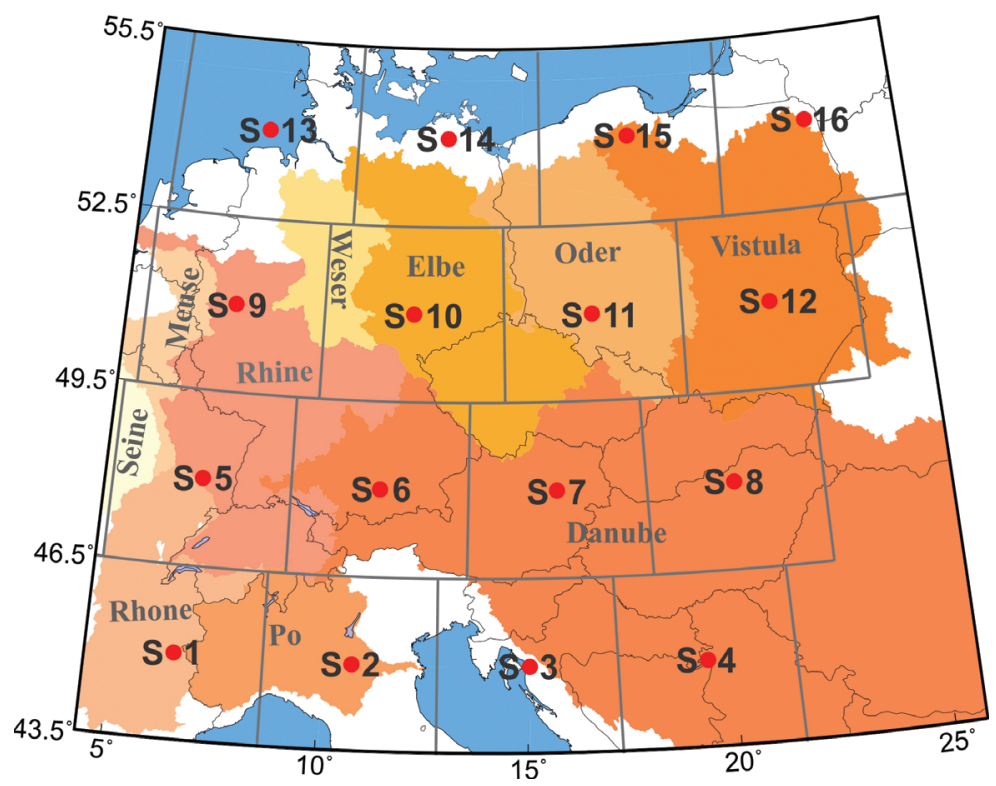

Fig. 1. The study area, including sixteen subareas (S1, S2, .., S16) as well as major river basins 


\section{Methodology}

In this investigation, temporal variations of height anomalies, temporal variations of vertical displacements and physical height changes over Central Europe have been determined using GFZ RL05 GRACE-based GGMs, specified in the section 2. The main computation steps and equations applied for the determination of those gravity and mass loading functionals are described in the section 3.1. The physical height changes obtained have been analysed and modelled. The approaches implemented for the analysis and modelling tasks are described in the section 3.2.

\subsection{Computation of physical height changes}

Height anomalies $\zeta$ have been determined using the ICGEM calculation service (cf. http://icgem.gfz-potsdam.de/ICGEM/.html; Barthelmes, 2016). The mathematical formulation applied to compute the $\zeta$ value at point $P$ on the ellipsoid at the ICGEM can be written as follows (cf. Eq. (116) in Barthelmes, 2013; pp. 22)

$$
\begin{aligned}
\zeta(\varphi, \lambda)= & \frac{G M}{r_{e} \gamma\left(r_{e}, \varphi\right)} \sum_{l=0}^{l_{\max }}\left(\frac{R}{r_{e}}\right)^{l} \sum_{m=0}^{l} P_{l m}(\sin \varphi)\left(C_{l m}^{T} \cos m \lambda+S_{l m}^{T} \sin m \lambda\right) \\
& -\frac{2 \pi G \rho}{\gamma\left(r_{e}, \varphi\right)}\left[R \sum_{l=0}^{l_{\max }} \sum_{m=0}^{l} P_{l m}(\sin \varphi)\left(C_{l m}^{\text {topo }} \cos m \lambda+S_{l m}^{\text {topo }} \sin m \lambda\right)\right]^{2}
\end{aligned}
$$

where $\varphi$ and $\lambda$ are the latitude and the longitude of $P$, respectively, $G M$ is the product of the Newtonian gravitational constant $G$ and the Earth's mass $M, r_{e}$ is the radius of $P, \gamma\left(r_{e}, \varphi\right)$ presents the normal gravity at $P, C_{l m}^{T}$ and $S_{l m}^{T}$ are differences between the Stokes' coefficients $\bar{C}_{l m}$ and $\bar{S}_{l m}$ and spherical harmonic coefficients $C_{l m}^{U}$ and $S_{l m}^{U}$ of the normal potential $U, \rho$ presents a constant mass density, $C_{l m}^{t o p o}$ and $S_{l m}^{t o p o}$ are spherical harmonic coefficients of the topography, $R$ is the Earth's mean radius, $P_{l m}$ are normalized Legendre functions of degree $l$ and order $m, l_{\max }$ is the applied maximum degree (in this study $l_{\max }=60$, that corresponds to the spatial resolution represented by the size of the abovementioned sixteen areas).

Temporal variations of height anomalies $\Delta \zeta$ were calculated as follows:

$$
\Delta \zeta_{i}=\zeta_{i}-\zeta_{\text {mean }}
$$

where $i$ denotes the consecutive month in the time series and $\zeta_{\text {mean }}$ is the mean value obtained from all $\zeta_{i}$ in the time series.

Vertical displacements, i.e. displacements $d r$ of the Earth's surface in the radial direction, were determined as follows (van Dam et al., 2007): 


$$
d r(\varphi, \lambda)=R \sum_{l=1}^{l_{\max }} \sum_{m=0}^{l} P_{l m}(\sin \varphi) \cdot\left(\bar{C}_{l m} \cos m \lambda+\bar{S}_{l m} \sin m \lambda\right) \frac{h_{l}^{\prime}}{1+k_{l}^{\prime}}
$$

where $h_{l}^{\prime}$ and $k_{l}^{\prime}$ are the load Love numbers of degree $l$.

As in the case of $\Delta \zeta$, temporal variations of vertical displacements $\Delta d r$ were calculated by subtracting the mean value $d r_{\text {mean }}$ from the time series of vertical displacements

$$
\Delta d r_{i}=d r_{i}-d r_{\text {mean }}
$$

Assuming that temporal variations of ellipsoidal heights $\Delta h$ are represented by temporal variations of vertical displacements $\Delta d r$, physical height (represented by the normal height) changes $\Delta H$ can be estimated as follows:

$$
\Delta H_{i}=\Delta d r_{i}-\Delta \zeta_{i}
$$

\subsection{Analysis and modelling of physical height changes}

Physical height changes obtained with the use of Eq. (5) have been analyzed and modelled using two methods: the seasonal decomposition method (e.g. Makridakis et al., 1998) and the PCA/EOF (Principal Component Analysis/Empirical Orthogonal Function) method (e.g. Jolliffe, 2002). The main aim of the seasonal decomposition method is to decompose physical height changes in the time domain, while in order to analyse physical heights changes in spatio-temporal domain the PCA/EOF method is employed. Several authors demonstrated the usefulness of the seasonal decomposition method and the PCA/EOF method for the analysis and modelling of time series of the functionals of functionals of the Earth gravitational field (e.g. Rangelova, 2007; Krynski et al., 2014; Godah et al., 2017). The investigated methods can be described in short as follows:

In the seasonal decomposition method physical height changes $\Delta H$ were decomposed into

$$
\Delta H_{i}=T_{i}+S_{i}+E_{i}
$$

where $S$ presents a seasonal component, $T$ is a long term/trend component and $E$ denotes an unmodelled component. The model $\Delta H^{\mathrm{SD}}$ of physical height changes $\Delta H$ developed with the use of the seasonal decomposition method consists of the sum of seasonal and long term/trend components

$$
\Delta H^{\mathrm{SD}}=T+S
$$


The periodicities in $\Delta H$ time series investigated were estimated from the periodogram values $P$ that are computed as follows (see Eq. (13.1.4) in Wei, 2006; p. 290):

$$
P_{i}=\left(a_{i}^{2}+b_{i}^{2}\right) \frac{M}{2}
$$

where $a$ and $b$ are Fourier coefficients and $M$ presents number of elements in the time series investigated. The computational algorithm implemented for the seasonal decomposition method is described in Godah et al. (2017).

In the PCA/EOF method, $\Delta H_{i}$ time series $(i=1,2,3, \ldots, 84)$ from the aforementioned sixteen subareas inserted to the matrix $\Delta \mathbf{H}$, can be represented by the product of two matrices $\mathbf{T}$ and $\mathbf{P}$,

$$
\Delta \mathbf{H}=\mathbf{T} \mathbf{P}^{\mathrm{T}}+\boldsymbol{\varepsilon}
$$

where $\mathbf{T}$ consists of principal component analysis (PCA) modes, $\mathbf{P}$ is the loading matrix that defines the EOF loading patterns and reflects contributions of original variables to various PCA modes, and the matrix $\varepsilon$ presents unmodelled parts of $\Delta H$ time series.

The PCA/EOF method relies on finding matrices $\mathbf{P}$ and $\mathbf{T}$. In this study, those matrices were estimated using the SVD (Singular Value Decomposition) algorithm implemented in the MATLAB software, in particular, the function "pca" (https:// www.mathworks.com/help/stats/pca.html). The fraction of the total variance of $\Delta H$ reflected by the PCA mode $j$ was estimated as follows:

$$
\sigma_{j}=\frac{\lambda_{j}}{\Delta},(j=1,2,3, \ldots, 16)
$$

where $\lambda_{j}$ denotes the eigenvalue estimated from $\Delta \mathbf{H}$, and variable $\Delta$ is the total variance of temporal variations of normal heights $\Delta H$.

The model $\Delta H^{\mathrm{PCA} / \mathrm{EOF}}$ of physical height changes $\Delta H$

$$
\Delta H^{\mathrm{PCA} / \mathrm{EOF}}=\sum_{s=1}^{k} \mathrm{PCA}_{s} \cdot \mathrm{EOF}_{s}
$$

was developed with the use of the PCA/EOF method. The variable $k$ denotes the number of PCA modes and EOF loading patterns required to reflect the significant signal, e.g. more than $95 \%$ in terms of total variance, of temporal variations of normal heights. 


\section{Results}

Temporal variations of height anomalies, temporal variations of vertical displacements and physical height changes over Central Europe estimated for the period between $01 / 2004$ and 12/2010 using GRACE data specified in the section 2, are given in the section 4.1. The section 4.2 provides the results of the analysis and modelling of the obtained physical height changes.

\subsection{Temporal variations of height anomalies, vertical displacements and physical height changes}

Maps of temporal variations of height anomalies $\Delta \zeta$ determined with use of Eq. (2), temporal variations of vertical displacements $\Delta d r$ obtained using Eq. (4) and physical height changes $\Delta H$ estimated with Eq. (5) are shown in Figure 2. They indicate that maximum values of $\Delta \zeta$ are observed in February-April and minimum values in August-October. For $\Delta d r$, maximum values are observed in August-October and minimum values in February-April which correspond to minima and maxima of $\Delta \zeta$, respectively. For the same subarea, the dispersions of $\Delta \zeta$ and $\Delta d r$ reach $9.6 \mathrm{~mm}$ and $13.6 \mathrm{~mm}$, respectively. The combination of $\Delta \zeta$ and $\Delta d r$ lead to temporal variations of physical heights $\Delta H$ of minimum values observed in February-April and maximum values observed in August-October. The $\Delta H$ can reach up to $22.8 \mathrm{~mm}$ for the same subarea.

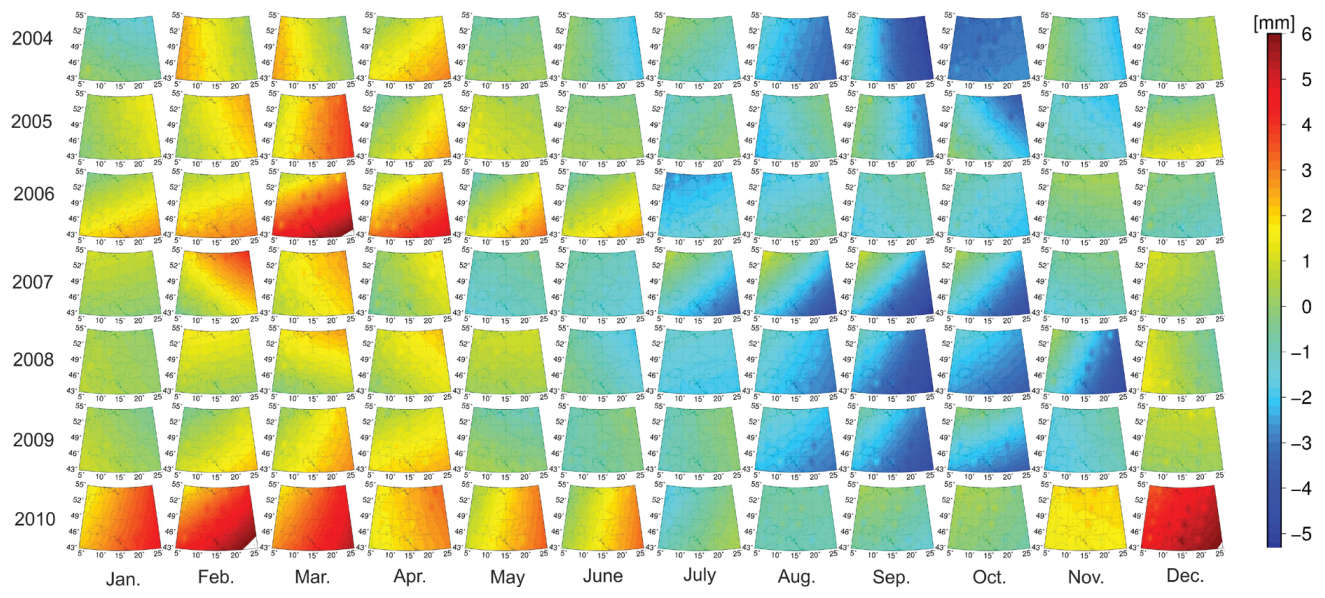

Fig. 2a. Maps of height anomaly variations $\Delta \zeta$ 


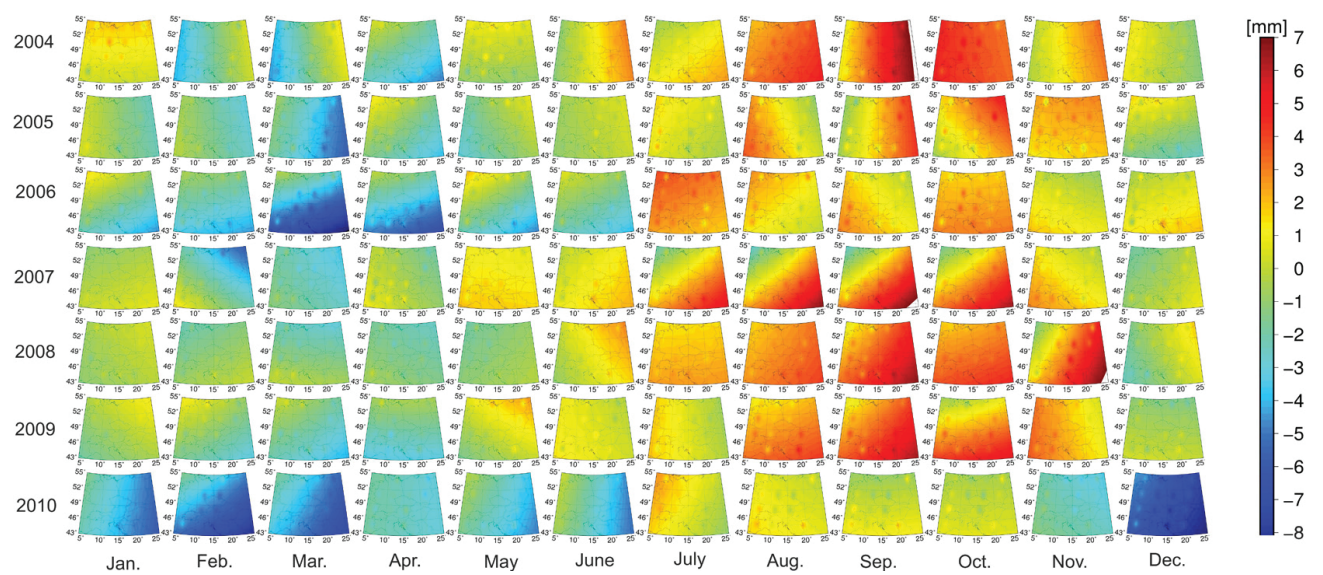

Fig. 2b. Maps of temporal variations of vertical displacements $\Delta d r$

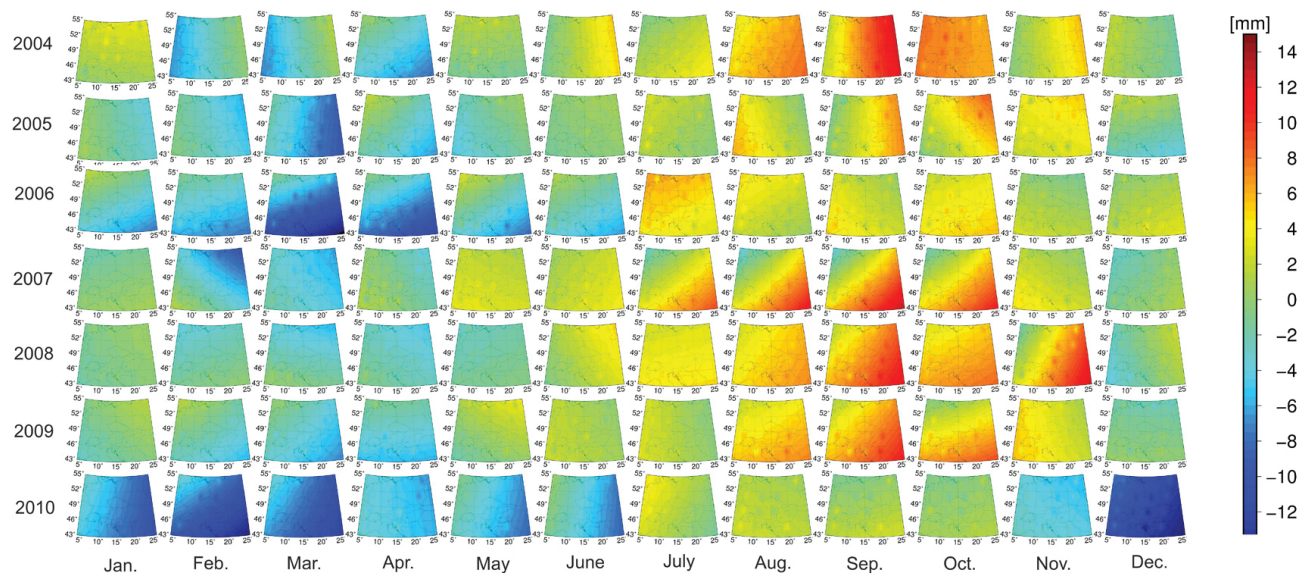

Fig. 2c. Maps of physical height changes $\Delta H$

\subsection{Analysis and modelling of physical height changes}

Figure 3 shows periodogram values $P$ computed from $\Delta H$ time series for subareas 1 , $2, \ldots, 16$ using Eq. (8). It indicates a distinctive one year periodicity, as dominant for all subareas, in $\Delta H$ time series. 


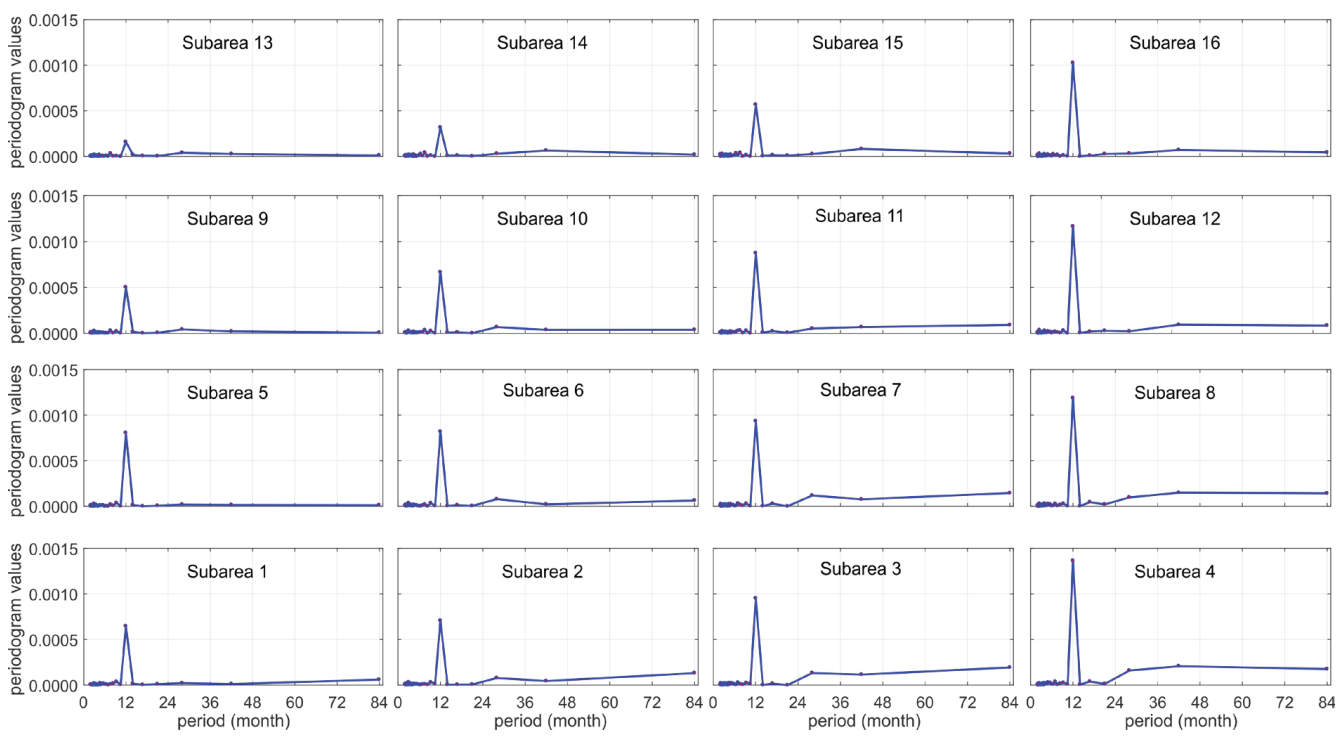

Fig. 3. Periodicity of physical height changes $\Delta H$

Physical height changes $\Delta H$ presented in the section 4.1 (cf. Figure 2c) have been decomposed into seasonal $S$, long term/trend $T$ and unmodelled $E$ components. Taking into the concideration the annual periodicity (Figure 3) of the seasonal component, the seasonal decoposition method presented in the section 3.2 has been used. Figure 4 shows time series of physical height changes and their components for each subarea.

The results presented in Figure 4 indicate a seasonal component as a dominant part of $\Delta H$ time series. They also show that peaked predominantly values of seasonal components of physical height changes for all subareas are observed in spring and fall seasons. The amplitudes of those seasonal components strongly depend on the subarea investigated. For instance, the largest amplitude, i.e. $\pm 7 \mathrm{~mm}$, of the seasonal component is found in the subarea 4 , while the lowest one, i.e. $\pm 2 \mathrm{~mm}$, is found in the subarea 13. This might be ascribed to the fact that the major source of temporal mass variations for the subarea 4 located in the Danube basin, is strongly related to temporal variations of total water storage (see Springer et al., 2017). The sea level changes and sediment deposition in the shallow sea, e.g. the North Sea, can be considered as one of the main sources of temporal mass variations in the subarea 13, and therefore, physical height changes within that subarea. The amplitudes of the seasonal component of $\Delta H$ time series for the remaining subares range from $\pm 2 \mathrm{~mm}$ to $\pm 7 \mathrm{~mm}$. Figure 4 also indicates consistency for long term/trend components of $\Delta H$ for subareas located within the same catchment. For instance, long term/trend components of $\Delta H$ for subareas 3, 4, 7 and 8 that are located in the Danube basin are in a good agreement. The long term/trend components of $\Delta H$ for subareas $3,4,7$ and 8 descend from 01/2004 to 03/2006 then ascend to authmn 2007 and descend again. 


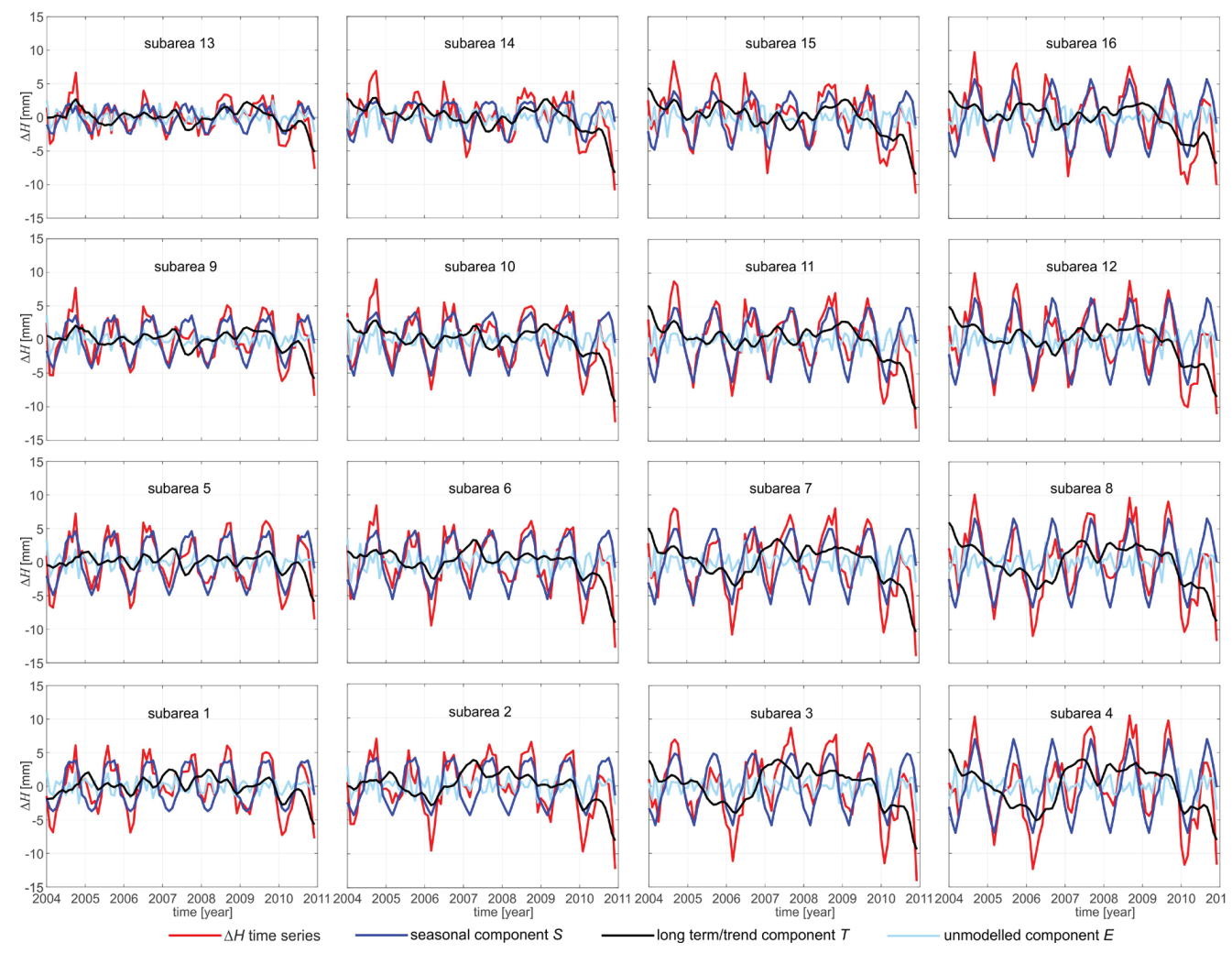

Fig. 4. Physical height changes and their components obtained with the use of the seasonal decomposition method

The correlation between long term/trend components of $\Delta H$ for subareas $3,4,7$ and 8 reaches up to $96.8 \%$.

The physical height changes have also been analysed using the PCA/EOF method. The percentages of total variance of $\Delta H$ reflected by PCA modes and EOF loading patterns obtained using Eq. (9), are shown in Figure 5. They indicate that the first three PCAs/EOFs reflect $95.9 \%$ of $\Delta H$ signal in terms of total variances. The first three PCAs/EOFs are illustrated in Figures 6 and 7. 


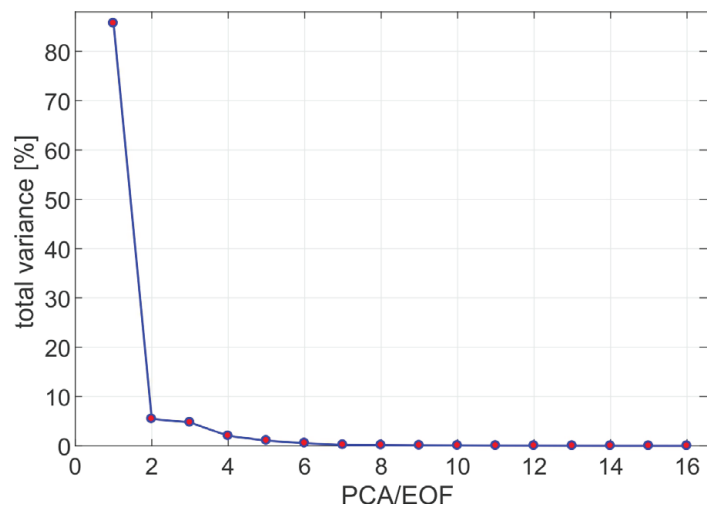

Fig. 5. The percentages of total variance of $\Delta H$ reflected by PCAs/EOFs

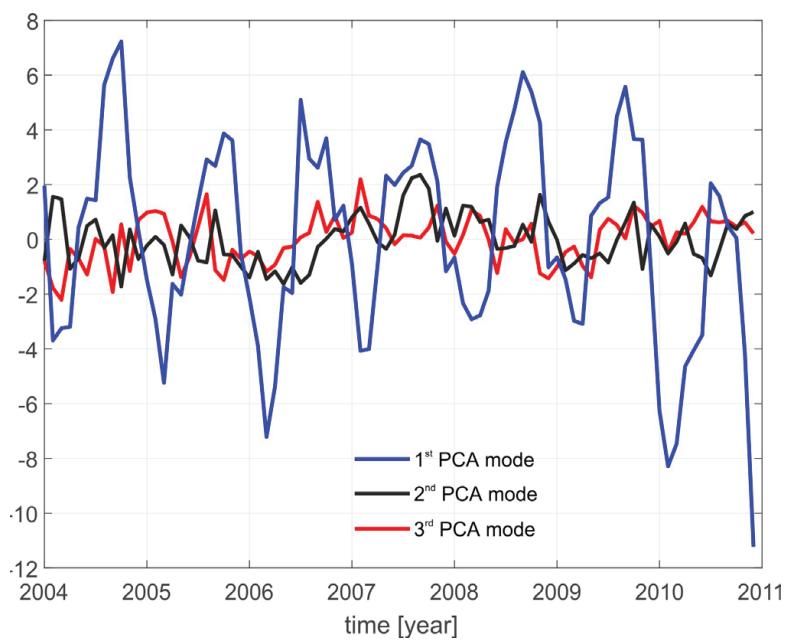

Fig. 6. Time series of first three PCA modes
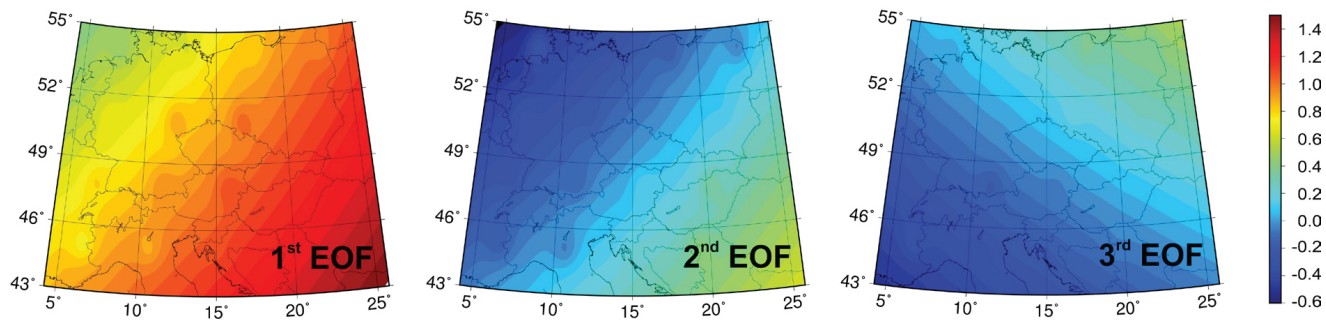

Fig. 7. First three EOF loading patterns 
The results presented in Figures 5-7 show that significant part of the signal $(\sim 85.7 \%)$ in $\Delta H$, in terms of total variance, can be estimated from the first PCA/EOF. The first PCA illustrates a distinctive seasonal pattern, with minimum values in February-April and maximum values in July-September, for the whole area investigated. The first EOF reveals clear slope from South-East to North-West for physical height changes. This slope pattern might be correlated with the water influx from the major rivers basins within the area investigated (cf. Figure 1). The $2^{\text {nd }}$ and $3^{\text {rd }}$ PCAs/EOFs reflect $\sim 10.2 \%$ of total variance of $\Delta H$.

For all subareas investigated, $\Delta H^{\mathrm{SD}}$ and $\Delta H^{\mathrm{PCA} / \mathrm{EOF}}$ models have been developed on the basis of the seasonal $S$ and long term/trend $T$ components obtained using the seasonal decomposition method and the first three PCA modes and EOF loading patterns estimated using Eq. (11). Figure 8 shows these models versus the respective $\Delta H$ data determined using Eq. (5). The statistics reflecting the fit of $\Delta H^{\mathrm{SD}}$ and $\Delta H^{\mathrm{PCA} / \mathrm{EOF}}$ models to $\Delta H$ data, are given in Table 1 .

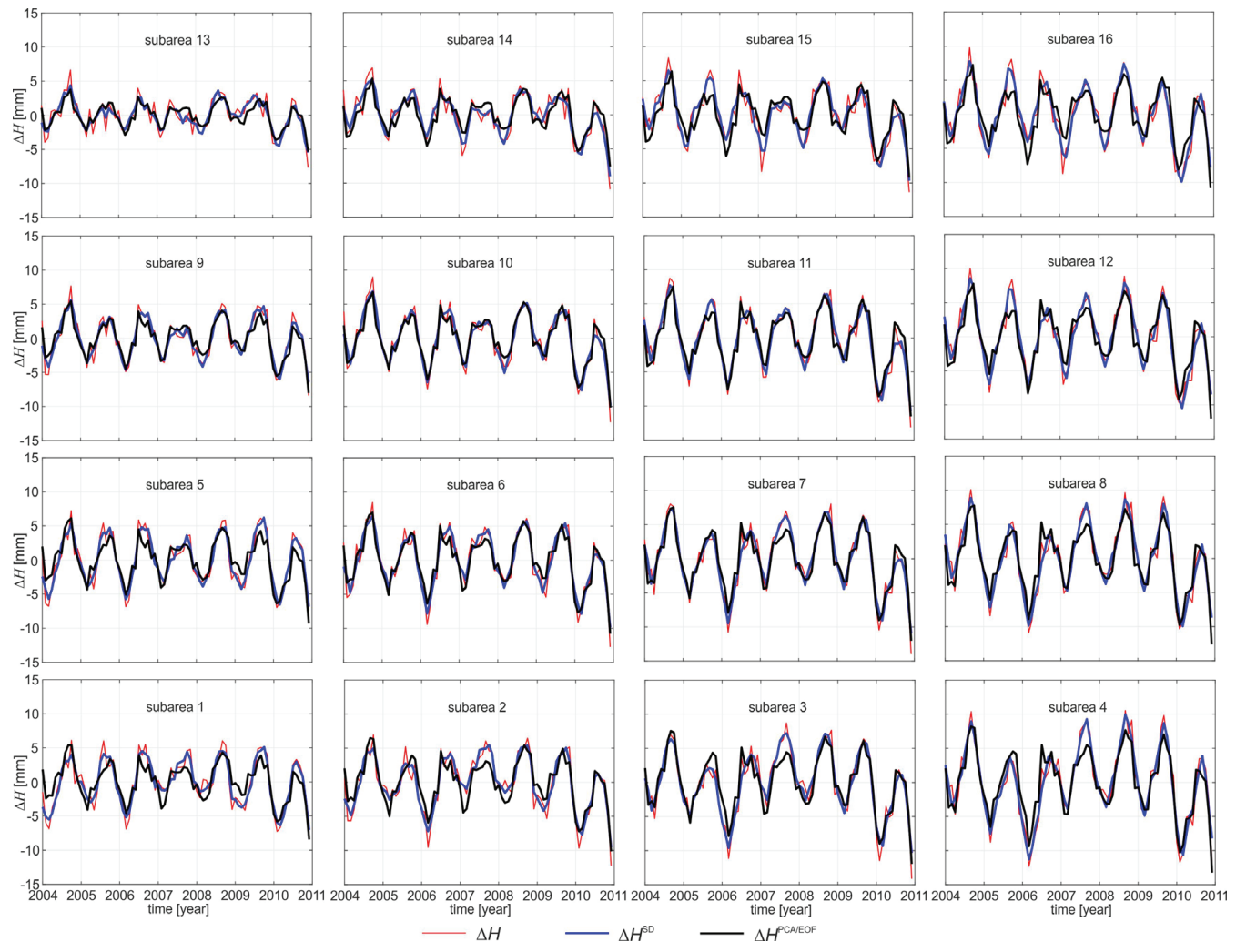

Fig. 8. Physical height changes and their models developed with the use of the seasonal decomposition method $\left(\Delta H^{\mathrm{SD}}\right)$ and the PCA/EOF method $\left(\Delta H^{\mathrm{PCA} / \mathrm{EOF}}\right)$ 
Table 1. Statistics of differences between normal height changes estimated from GRACE mission data and their respective models developed using the seasonal decomposition method $\left(\Delta H^{\mathrm{SD}}\right)$, and the PCA/EOF method $\left(\triangle H^{\mathrm{PCA} / \mathrm{EOF}}\right)[\mathrm{mm}]$

\begin{tabular}{|c|c|c|c|c|c|c|c|c|}
\hline \multirow{2}{*}{ Subarea } & \multicolumn{5}{|c|}{$\Delta H-\Delta H^{\mathrm{SD}}$} & \multicolumn{4}{c|}{$\Delta H-\Delta H^{\mathrm{PCA} / \mathrm{EOF}}$} \\
\cline { 2 - 9 } & $\min$ & $\max$ & $\operatorname{mean}$ & std. & $\min$ & $\max$ & mean & std. \\
\hline S1 & -2.5 & 2.2 & 0.0 & 1.0 & -4.9 & 4.3 & 0.0 & 2.0 \\
\hline $\mathrm{S} 2$ & -2.7 & 2.9 & 0.0 & 1.2 & -3.6 & 4.1 & 0.0 & 1.8 \\
\hline S3 & -3.8 & 2.8 & 0.0 & 1.3 & -3.7 & 4.3 & 0.0 & 1.6 \\
\hline S4 & -3.5 & 3.0 & 0.0 & 1.4 & -4.5 & 4.1 & 0.0 & 1.9 \\
\hline S5 & -2.4 & 3.4 & 0.0 & 1.0 & -4.3 & 3.5 & 0.0 & 1.6 \\
\hline S6 & -3.0 & 3.6 & 0.0 & 1.3 & -3.0 & 2.8 & 0.0 & 1.2 \\
\hline S7 & -3.3 & 3.2 & 0.0 & 1.3 & -2.8 & 3.1 & 0.0 & 1.2 \\
\hline S8 & -3.0 & 3.0 & 0.0 & 1.3 & -3.1 & 3.6 & 0.0 & 1.6 \\
\hline S9 & -2.3 & 3.6 & 0.0 & 1.1 & -2.8 & 2.3 & 0.0 & 1.0 \\
\hline S10 & -2.9 & 3.3 & 0.0 & 1.2 & -2.2 & 2.2 & 0.0 & 0.9 \\
\hline S11 & -2.4 & 3.3 & 0.0 & 1.2 & -2.1 & 2.9 & 0.0 & 1.1 \\
\hline S12 & -2.8 & 2.9 & 0.0 & 1.3 & -3.4 & 4.6 & 0.0 & 1.7 \\
\hline S13 & -2.2 & 2.6 & 0.0 & 1.1 & -3.2 & 2.9 & 0.0 & 1.1 \\
\hline S14 & -2.9 & 2.6 & 0.0 & 1.2 & -3.4 & 2.5 & 0.0 & 1.4 \\
\hline S15 & -3.1 & 3.2 & 0.0 & 1.2 & -5.6 & 3.8 & 0.0 & 1.8 \\
\hline S16 & -3.0 & 2.6 & 0.0 & 1.2 & -5.5 & 4.8 & 0.0 & 2.0 \\
\hline
\end{tabular}

The results presented in Figure 8 reveal that $\Delta H^{\mathrm{SD}}$ obtained using the seasonal decomposition method and $\Delta H^{\mathrm{PCA} / \mathrm{EOF}}$ obtained using the PCA/EOF method fit quite well to $\Delta H$ data determined using Eq. (5). The correlations between the modelled $\Delta H$ and the respective $\Delta H$ data range from $89.5 \%$ to $96.2 \%$ for $\Delta H^{\mathrm{SD}}$ and from $82.5 \%$ to $98.8 \%$ for $\Delta H^{\mathrm{PCA} / \mathrm{EOF}}$. The results presented in Table 1 show that differences between $\Delta H$ obtained from the models and $\Delta H$ data range from $-3.8 \mathrm{~mm}$ to $3.6 \mathrm{~mm}$ for $\Delta H^{\mathrm{SD}}$

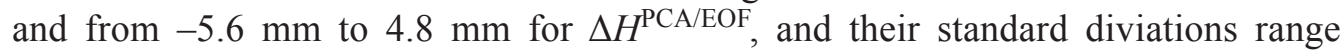
from $1.0 \mathrm{~mm}$ to $1.4 \mathrm{~mm}$ for the $\Delta H^{\mathrm{SD}}$ and from $0.9 \mathrm{~mm}$ to $2.0 \mathrm{~mm}$ for $\Delta H^{\mathrm{PCA} / \mathrm{EOF}}$. It indicates that $\Delta H^{\mathrm{SD}}$ model fits better to $\Delta H$ data than $\Delta H^{\mathrm{PCA} / \mathrm{EOF}}$ model. This might be due to the fact that $\Delta H^{\mathrm{SD}}$ values for each subarea are completely independent of $\Delta H$ values from other subareas while in the PCA/EOF method, $\Delta H$ values from all subareas contribute to the $\Delta H^{\mathrm{PCA} / \mathrm{EOF}}$ values for any subarea. The highest correlation (98.8\%) between $\Delta H^{\mathrm{PCA} / \mathrm{EOF}}$ values and the corresponding $\Delta H$ data has been observed in the subarea 10. This might be due to the fact that the $\Delta H$ time series for this subarea are the closest to the mean $\Delta H$ time series. 


\section{Conclusions and discussion}

Temporal variations of height anomalies and temporal variations of vertical displacements were discussed in the perspective of the estimation of physical height changes over Central Europe. The GFZ RL05 GRACE-based GGMs truncated at d/o 60 and filtered using the DDK3 filter were employed for the determination of those gravity and mass loading functionals.

Temporal variations of height anomalies and vertical displacements for the period between January 2004 and December 2010 were combined providing physical height changes which reach up to $22.8 \mathrm{~mm}$.

The obtained physical height changes were analyzed and modelled using the seasonal decomposition method and the principal component/empirical orthogonal function (PCA/EOF) method. It was found that the annual periodicity of physical height changes is a dominant one with minimum values observed in spring (FebruaryApril) and maximum values in autumn (August-October). Subareas located in the same catchment induce consistent long term/trend components of physical height changes, i.e. the correlation of long term/trend components can reach up to $96.8 \%$. The significant signal, i.e. greater than $95.8 \%$ terms of the total variance of physical height changes over Centre Europe can be obtained from the first three PCA modes and EOF loading patterns. The first PCA/EOF reflects $\sim 85.7 \%$ of total variance of physical height changes. The first EOF exhibit clear slope pattern, from South-East toward North-West, of physical height changes.

Models of physical height changes developed using the seasonal decomposition method are slightly better than the corresponding models developed using the PCA/ EOF method. They fit quite well, i.e. $89.5 \%-96.5 \%$ in terms of correlations, to their corresponding values determined from GRACE mission data. The standard deviations of differences between physical height changes estimated from GRACE mission data and the corresponding ones from models developed using the seasonal decomposition method do not exceed $1.4 \mathrm{~mm}$.

Overall, physical height changes estimated using GRACE mission data can play an essential role for the modernization of the vertical reference system over the area investigated. The final interpretation requires complementary studies concerning an understanding of the main sources of these changes, e.g. hydrology in inland areas and sediment and sea level changes in sea areas.

\section{Acknowledgements}

The research was conducted in the framework of the statutory project "Problems of geodesy and geodynamics" of the Institute of Geodesy and Cartography (IGiK), Warsaw, financially supported by the Polish Ministry of Science and Higher Education and the EPOS-PL (European Plate Observing System-Poland). 


\section{References}

Barthelmes, F. (2013). Definition of Functionals of the Geopotential and Their Calculation from Spherical Harmonic Models Theory and formulas used by the calculation service of the International Centre for Global Earth Models (ICGEM). The GFZ series, Scientific Technical Report (STR), STR 09/02, Revised Edition Jan. 2013, pp. 32.

Barthelmes, F. (2016). International Centre for Global Earth Models (ICGEM). J Geod. 90(10): 11771180, In: H. Drewes, F. Kuglitsch, J. Adám, S. Rózsa (eds) The Geodesists Handbook 2016. J. Geod., 90(10): 907-1205. https://doi.org/10.1007/s00190-016-0948-z

Dahle, C., Flechtner, F., Gruber, C., König, R., Michalak, G., Neumayer, K.-H. and König, D. (2014). GFZ RL05: An Improved Time-Series of Monthly GRACE Gravity Field Solutions. Observation of the System Earth from Space - CHAMP, GRACE, GOCE and future missions, Adv. Tech. in Earth Sci.: 29-39. https://doi.org/10.1007/978-3-642-32135-1

van Dam, T., Wahr, J. and Lavallée, D. (2007). A comparison of annual vertical crustal displacements from GPS and Gravity Recovery and Climate Experiment (GRACE) over Europe. J Geophys. Res., 112: B03404. https://doi.org/10.1029/2006JB004335

Dziewonski, A.M. and Anderson, D.L. (1981). Preliminary reference Earth model. Phys. Earth Planet. Int., 25:297-356. https://doi.org/10.1016/0031-9201(81)90046-7

Eriksson, D. and MacMillan, D.S. (2014). Continental hydrology loading observed by VLBI measurements. J. Geod., 88(7), 675-690. https://doi.org/10.1007/s00190-014-0713-0

Godah, W., Szelachowska, M. and Krynski, J. (2017). On the analysis of temporal geoid height variations obtained from GRACE-based GGMs over the area of Poland. Acta Geoph., 65(4), 713-725. https://doi.org/10.1007/s11600-017-0064-3

Gua, Y., Yuana, L., Fana, D., Youa, W. and Suc, Y. (2017). Seasonal crustal vertical deformation induced by environmental mass loading in mainland China derived from GPS, GRACE and surface loading models. Advances in Space Research 59(1): 88-102. https://doi.org/10.1016/j.asr.2016.09.008

Jolliffe, I. (2002). Principal component analysis. $2^{\text {nd }}$ Edn, John Wiley \& Sons, Ltd.

Krynski, J., Kloch-Główka, G. and Szelachowska, M. (2014). Analysis of time variations of the gravity field over Europe obtained from GRACE data in terms of geoid height and mass variations. In: C. Rizos, P. Willis (eds), Earth on the Edge: Science for a Sustainable Planet, IAG Symposia, 139, 365-370. https://doi.org/10.1007/978-3-642-37222-3_48

Kusche, J. and Schrama, E.J.O. (2005). Surface mass redistribution inversion from global GPS deformation and Gravity Recovery and Climate Experiment (GRACE) gravity data. J. Geophys. Res., 110, B09409. https://doi.org/10.1029/2004JB003556

Kusche, J. (2007). Approximate decorrelation and non-isotropic smoothing of time variable GRACEtype gravity field models. J. Geod., 81(11): 733-749. https://doi.org/10.1007/s00190-007-0143-3

Kusche, J., Schmidt, R., Petrovic, S. and Rietbroek, R. (2009). Decorrelated GRACE time-variable gravity solutions by GFZ, and their validation using a hydrological model. J. Geod., 83(10): 903-913. https://doi.org/10.1007/s00190-009-0308-3

Makridakis, S., Wheelwright, S.C. and Hyndman, R.J. (1998). Forecasting: Methods and applications. $3^{\text {rd }}$ Edition, New York: Wiley, 656 pp., ISBN: 978-0-471-53233-0.

Pan, Y., Shen, W-B., Hwang, C., Liao, C., Zhang, T. and Zhang G. (2016). Seasonal Mass Changes and Crustal Vertical Deformations Constrained by GPS and GRACE in Northeastern Tibet. Sensors (Basel, Switzerland), 16(8): 1211. https://doi.org/10.3390/s16081211

Rangelova, E. (2007). A dynamic geoid model for Canada, PhD. Thesis, University of Calgary. Department of Geomatics Engineering, Report No. 20261.

Rangelova, E. and Sideris, M.G. (2008). Contributions of terrestrial and GRACE data to the study of the secular geoid changes in North America. J. Geodyn., 46(3): 131-143. https://doi.org/10.1016/j. jog.2008.03.006 
Rangelova, E., Fotopoulos, G. and Sideris, M.G. (2010). Implementing a dynamic geoid as a vertical datum for orthometric heights in Canada. In: S.P.P. Mertikas (ed), Gravity, Geoid and Earth Observation, IAG Commission 2 Gravity Field, Chania, Greece, IAG Symposia, 135: 295-302, June 23-27, 2008, Springer. https://doi.org/10.1007/978-3-642-10634-7_38

Springer, A., Eicker, A., Bettge, A., Kusche, J. and Hense, A., (2017). Evaluation of the Water Cycle in the European COSMO-REA6 Reanalysis Using GRACE. Water, 9(4): 289. https://doi.org/10.3390/ w9040289

Tan, W., Dongb, D., Chena, J. and Wua, B. (2016). Analysis of systematic differences from GPSmeasured and GRACE-modeled deformation in Central Valley, California. Advances in Space Research, 57(1): 19-29. https://doi.org/10.1016/j.asr.2015.08.034

Tapley, B.D., Bettadpur, S., Watkins, M. and Reigber, C. (2004). The gravity recovery and climate experiment: Mission overview and early results. Geophys. Res. Lett., 31, L09607, https://doi. org/10.1029/2004GL019920

Wang, H., Xiang, L., Jia, L., Jiang, L., Wang, Z., Hu, B. and Gao, P. (2012). Load Love numbers and Green's functions for elastic Earth models PREM, iasp91, ak135, and modified models with refined crustal structure from Crust 2.0. Computers \& Geosciences, 49:190-199. https://doi.org/10.1016/j. cageo.2012.06.022

Wang, S., Chen, J., Li, J., Hu, X. and Ni, S. (2016). Geophysical interpretation of GPS loading deformation over western Europe using GRACE measurements. Annals of Geophysics, (59)5: S0538. https://doi.org/10.4401/ag-7058

Watkins, M.M, Wiese, D.N, Yuan, D.N, Boening, C. and Landerer, F.W. (2015). Improved methods for observing Earth's time variable mass distribution with GRACE using spherical cap mascons. J Geophys. Res. Solid Earth, 120(4): 2648-2671. https://doi.org/10.1002/2014JB011547

Wei, W., (2006). Time Series Analysis: Univariate and Multivariate Methods. $2^{\text {nd }}$ Edn, Pearson Addison Wesley, 2006 - Mathematics, 614 pp.

Wouters, B., Bonin, J.A., Chambers, D.P., Riva, R.E., Sasgen, I. and Wahr, J. (2014). GRACE, time-varying gravity, Earth system dynamics and climate change. Rep. Prog. Phys., https://doi. org/10.1088/0034-4885/77/11/116801 